\title{
The Monitoring of Brain Edema and Intracranial Hypertension
}

\author{
Mohammad I Hirzallah, MD and H. Alex Choi, MD, MS \\ Department of Neurosurgery and Neurology, University of Texas Health Science Center at Houston- McGovern Medical School, Houston, TX, USA
}

Preventing secondary brain injury after neurological insults is one of the primary goals of the neurocritical care unit. Our understanding of the roles of intracranial pressure (ICP) and cerebral edema in managing patients in the neurocritical care units is still evolving. Recent clinical trials examining the monitoring and treatment of elevated ICP have influenced the way we think about intracranial hypertension. Additionally, new methods of monitoring ICP, new physiologic surrogates derived from ICP measurements, and evolving technology to measure cerebral edema are currently being studied and tested for clinical efficacy. In this article, we will discuss both traditional and novel methods of monitoring ICP and cerebral edema.

J Neurocrit Care 2016;9(2):92-104

Key words: Intracranial pressure; Intracranial hypertension; Cerebral edema; Neurocritical Care

\author{
Received November 4, 2016 \\ Revised November 15, 2016 \\ Accepted November 17, 2016 \\ Corresponding Author: \\ H. Alex Choi, MD, MS \\ Department of Neurosurgery and \\ Neurology, University of Texas Health \\ Science Center at Houston-McGovern \\ Medical School, 6431 Fannin, MSB \\ 7.154, Houston, TX 77030, USA \\ Tel: $+1-713-500-7025$ \\ Fax: +1-713-500-0665 \\ E-mail: Huimahn.A.Choi@uth.tmc.edu
}

Copyright $\odot 2016$ The Korean Neurocritical Care Society

\section{INTRODUCTION}

Recent studies investigating the clinical utility of intracranial pressure (ICP) monitoring, ${ }^{1,2}$ hemicraniectomy for the treatment of elevated ICPs ${ }^{3,4}$ and hypothermia for elevated $\mathrm{ICPS}^{5}$ have contributed significantly to our understanding of ICP management and treatment. However, these studies have also demonstrated our limited understanding of the clinical significance of ICP and brain edema.

Almost two centuries ago, Monro and Kellie started the work that has been the basis of our understanding of cerebral hemodynamics and ICP. The "Monro-Kellie Doctrine," coined by Harvey Cushing, states with an intact skull, the sum of the volume of brain, blood and CSF is constant: an increase in one causing a decrease in one or both of the remaining two. ${ }^{6}$ The doctrine describes our ability to mea- sure pressure to extrapolate changes in volume representing cerebral edema or other space occupying lesions. When the cerebral perfusion concept was introduced, there was a shift in focus from cerebral volume to pressure. ${ }^{\text {? }}$

A normal ICP does not equate to a normal brain. Physiologic changes often precede increases in ICP. In addition, while a normal brain might exhibit very little ICP variations in its different compartments, a diseased brain will often exhibit compartmentalization of ICP between the two hemispheres across the falx cerebri and across the tentorium cerebri between the infra- and supra-tentorial compartments. This seems to precede a more generalized ICP increase as injury progresses and is important when considering the type and optimal placement of ICP monitoring devices. ${ }^{8-12}$

In this review, we will stress the importance of ICP as a

(cc) This is an Open Access article distributed under the terms of the Creative Commons Attribution Non-Commercial License (http://creativecommons.org/licenses/by$\mathrm{nc} / 4.0$ ) which permits unrestricted non-commercial use, distribution, and reproduction in any medium, provided the original work is properly cited. 
surrogate marker of increased intracranial volume. We will discuss the monitoring of ICP, non-invasive methods of ICP monitoring and novel methods of brain edema monitoring.

The results of the BEST-TRIP trial showing no difference in outcomes between a treatment protocol based on ICP monitoring versus that based on imaging and clinical examination has forced a re-examination of ICP thresholds. ${ }^{2}$ The Brain Trauma Foundation previously promoted treatment of ICP a threshold of above $20 \mathrm{mmHg} .{ }^{13}$ However, the recent recommendation included in the 2016 Brain Trauma Foundation Guidelines suggests treating ICP above $22 \mathrm{mmHg}$ because values above this level have been associated with increased mortality. ${ }^{14}$ Of course this value should be repeatedly corroborated by physical exam and imaging as herniation syndromes have been reported with ICPs less than $20 \mathrm{mmHg} .{ }^{15,16}$ The change in recommendation by 2 $\mathrm{mmHg}$ demonstrates the uncertainty around the importance of ICP monitoring and our limited knowledge of the importance of "threshold" values. At the bedside when managing patients with ICP monitors, $2 \mathrm{mmHg}$ is likely not a significant difference and ICP often will fluctuate significantly with very little changes in the patient's condition. Many researchers have postulated that individualized thresholds are more important than generalized ones as each patient's physiology is different. Although in concept individualized thresholds are an attractive idea, the methods for creating them have not been well developed.

\section{ICP WAVEFORMS}

Interpretation of ICP wave forms may give us additional information about brain edema by giving us insight into brain compliance and the state of cerebrovascular autoregulation. ${ }^{17}$ This is specifically important given that different patients can have different critical ICP values reflecting differences in brain compliance. ${ }^{18}$ In addition, being comfortable with interpreting waveforms allows the examiner to exclude artifacts such electrostatic discharges that could lead to artificial spikes in ICP values. ${ }^{19}$ Interpreting ICP waveforms can be done by looking at the appearance of single waves and looking at the trend of the ICP tracing over time.

When looking at a single ICP waveform, the examiner can identify 3 peaks (P1, P2 and P3) that correlate with the propagation of the arterial pulse pressure. ${ }^{20,21} \mathrm{P} 1$ (also referred to as systolic or percussion wave) is produced by the transmission of arterial pressure through the choroid plexus into the ventricles. P2 (tidal wave) is thought to reflect brain tissue compliance as the arterial pulse pressure further propagates into the brain parenchyma. P3 (dicrotic wave) reflects the arterial dicrotic notch which is due to the closure of the aortic valve. P1 usually has a higher amplitude than P2. It is noted that as intracranial volume and pressure increase and brain compliance decreases, it is common to observe P2 > P1. This reflects decreased brain compliance and impending herniation (Fig. 1). 8,17,20,21.

By monitoring ICP tracings over time dangerous patterns can be identified. Lundberg A waves (Fig. 2), also called Plateau waves, are ICP increases for a period of 5 to 10 minutes. They reflect reduced cerebral compliance and

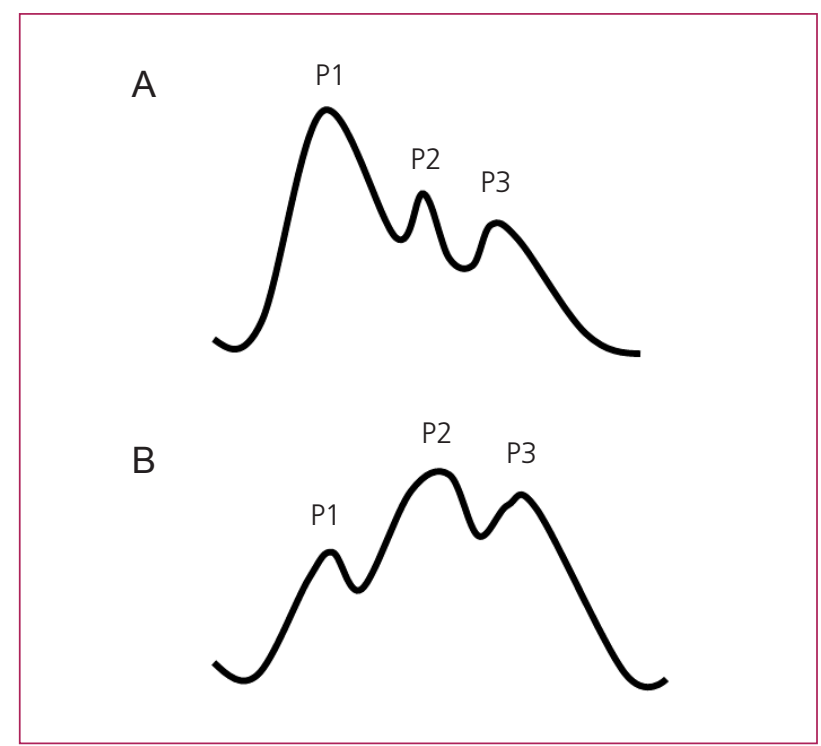

Figure 1. The correlation between ICP waveform and autoregulation. (A) P1 > P2 reflects a good compliance waveform with functional autoregulation. (B) As the brain loses its compensatory reserve, the volume increases are no longer offset by compensatory mechanisms including changes in vascular resistance and displacement of CSF and venous blood towards the spinal cord spaces. This results in increase in ICP and a shift to a poor compliance waveform (P2>P1). CSF, cerebrospinal fluid; ICP, intracranial pressure. 

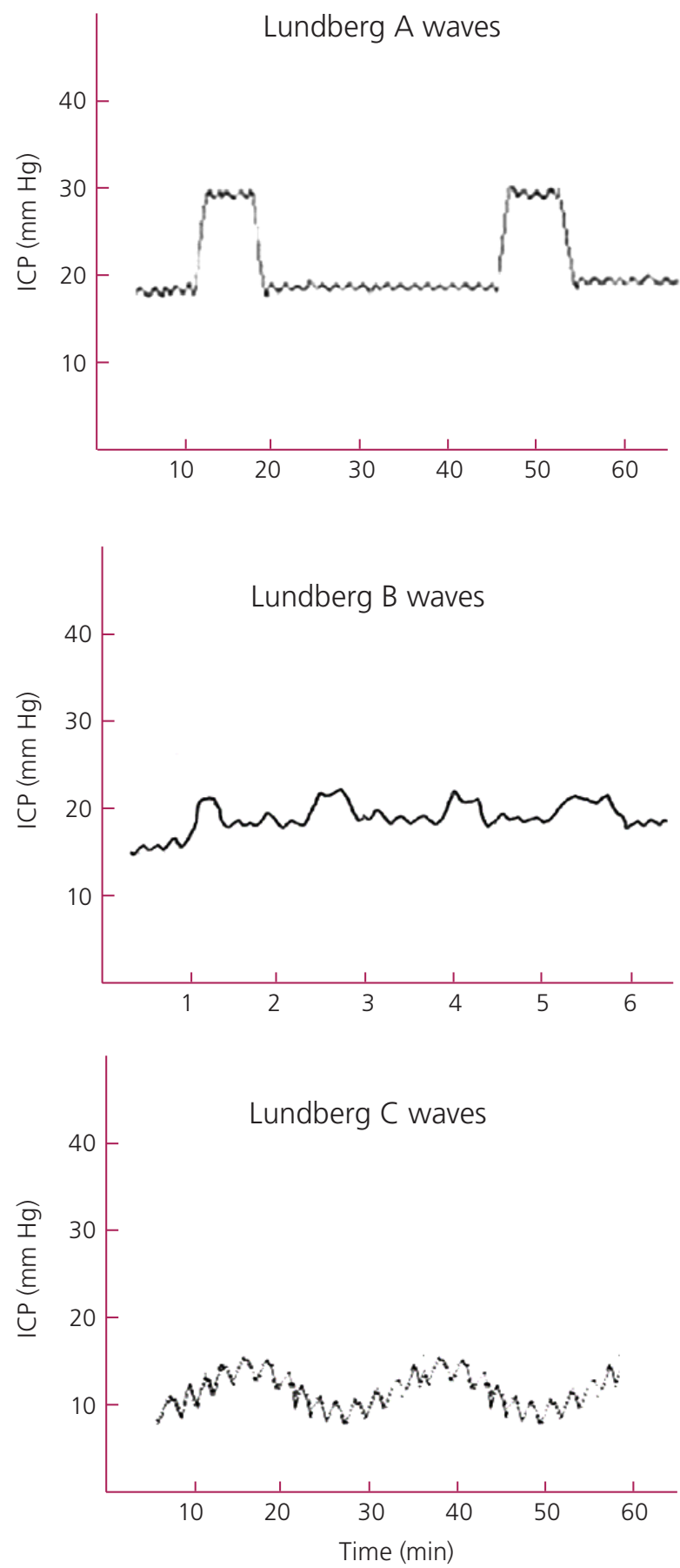

Figure 2. Lundberg waves. Lundberg A waves are ICP increases for 5 to 10 minutes. They reflect reduced cerebral compliance and impending herniation. Lundberg $B$ waves have unclear value in clinical practice. Lundberg $C$ waves are thought to reflect normal interactions between the cardiac and pulmonary cycles. ICP, intracranial pressure.

impending herniation. 22,23 Lundberg B waves (Fig. 2) were originally described as repeating elements in the ICP signal with frequencies of 0.5 to 2 waves per minute that reflect elevated ICP. ${ }^{23}$ However, the frequency range of Lundberg $B$ waves has been expanded to 0.3 to 3 waves per minute and they have been observed in normal subjects, ventilated patients and during sleep. Thus, the value of these waves in clinical practice remains under investigation. ${ }^{24}$ Lundberg C waves (Fig. 2) are oscillating waves at the frequency of 4-8 cycles per minute and are thought to reflect normal interactions between the cardiac and pulmonary cycles. ${ }^{8,23}$

\section{CALCULATED ICP VARIABLES}

Cerebral perfusion pressure (CPP) is the difference between the mean arterial pressure (MAP) and ICP. It reflects the pressure gradient across the intracranial vascular bed that drives cerebral blood flow (CBF) and subsequently, oxygen and metabolite delivery. The healthy brain utilizes autoregulation of its vasculature and blood flow to maintain constant CBF across a range of ICPS and MAPs. However, as the injured brain loses its capacity to autoregulate, maintaining CPP become crucial to prevent ischemia and secondary brain injury. ${ }^{8} \mathrm{CPP}$ above $60-70 \mathrm{mmHg}$ is recommended for improved survival and functional outcomes. ${ }^{14}$

Pressure reactivity index (PRx) is a measure of cerebrovascular reactivity. Cerebrovascular reactivity (the vasodilation of cerebral vessels in response to decreased systemic blood pressure and vice-versa) is one of the key cerebral autoregulatory mechanisms. ${ }^{25}$ With an intact pressure reactivity, increased mean arterial pressure (MAP) will lead to cerebral vasoconstriction within 5 to 10 seconds and subsequently a decrease in cerebral blood volume but no change in the ICP. The inverse happens with a decrease in MAP. PRx is the linear correlation coefficient between MAP and ICP changes over a 4-minute period and is reported as values ranging from -1 to +1 . A negative or zero value reflects a normally reactive vascular bed while positive values reflect passive, nonreactive vessels. ${ }^{26} \mathrm{PRx}$ reacts dynamically to CPP. PRx higher than 0.2 for more than 6 hours has been associated with increased mortality. ${ }^{27}$ One limitation to the clinical utility of PRx is the need for waveform 
data. Recently the Long-PRx (L-PRx) has been developed which allows similar measurements without the need for waveform measurements allowing for more widespread use. L-PRx is calculated using 20-minute averages of MAP and ICP data rather than beat-to-beat values. It is suggested that L-PRx values correlate with 6 month survival. ${ }^{28}$ However, it was more recently demonstrated that PRx may correlate better with mortality and severe disability than LPRx. Further studies and comparisons are needed. ${ }^{29}$

Correlation coefficient $(R)$ between the ICP wave amplitude (A) and the ICP (P) level (RAP) measures the correlation between the amplitude of the ICP waveform and the mean ICP value. This correlation coefficient is postulated to reflect the state of the brain's compensatory reserve and the patient's location on the pressure-volume curve. It is likely influenced by a combination of brain elasticity, pulsatile arterial inflow, and the delay of inflow and outflow of venous blood and CSF. RAP indicates how pulse amplitude of ICP correlates with the mean ICP over short periods of time (1-2 minutes). RAP value ranges from -1 to +1 . RAP close to +1 indicates that amplitude of ICP waves (AMP) vary according to changes in mean ICP. RAP close to -1 indicates that AMP decreases when mean ICP increases which would indicate increased intracranial volume and decreased autoregulatory reserve. RAP close to 0 indicates lack of synchronization between fast changes in amplitude and mean ICP. It has been shown that in patients who died from uncontrollable intracranial hypertension, RAP oscillated or decreased to 0 or negative values well before herniation. The combination of an ICP above $20 \mathrm{mmHg}$ for a period longer than 6 hours with low correlation between the amplitude and pressure $($ RAP $<0.5)$ was described as a predictor of unfavorable outcome. ${ }^{30}$ Baseline ICP measurement errors due to spontaneous drifts or shifts will effect RAP values accuracy. ${ }^{31}$

\section{INVASIVE METHODS OF MONITORING ICP}

Methods of ICP monitoring can be classified based on invasiveness, catheter location and transducer location. Invasive monitoring remains the gold standard and non- invasive options will be discussed in the next section under novel monitoring methods. Invasive catheters can be intraventricular or parenchymal (the two commonly used locations clinically). Subarachnoid, subdural and epidural devices have proven unreliable and are not used commonly in clinical practice. Pressure transducers can be intracranial within the catheter including fiberoptic or micro strain gauge transducers or extracranial strain gauge transducers that are coupled to the patient's intracranial space via fluid filled lines. ${ }^{8,32,33}$

External ventricular devices (EVD) are considered the gold standard for ICP monitoring., ${ }^{9,34}$ The advantages of EVD include global ICP measurements, allowing external calibration, recalibration of catheters in-situ, therapeutic interventions such as CSF drainage, and the administration of intrathecal medications. Disadvantages include placement difficulties with ventricular effacement in younger patients and with intracranial mass lesions. In addition to possibility of catheter occlusion, other disadvantages include increased infection and intracranial hemorrhage rates. ${ }^{8,9,35}$ Infection rates with EVD placement have been estimated to be as high as $11 \%$ in some case series. This is not mitigated by prophylactic catheter exchange. ${ }^{36,37}$ The use of antibiotic-impregnated EVD catheters can significantly reduce the risk of catheter-related infections. ${ }^{38}$ The rate of intracranial hemorrhages is estimated at 5.7\%. with the rate of clinically significant hemorrhages estimated at $0.61 \%{ }^{39}$

Microtransducer-tipped ICP device can be placed in the brain parenchyma via a small craniostomy. Advantages of these catheters include ease of placement, reliability in most clinical cases and lower infection rates. ${ }^{40}$ Disadvantages include inability to calibrate after placement, inability to drain CSF or inject medications, higher costs, and localized rather than global ICP measurements due to ICP gradients. ${ }^{10,33}$ Zero drift is another downside to using intraparenchymal catheters. However, newer catheters have lower rates of zero drift and good correlation with EVD measurements. ${ }^{41,42}$

The invasive tethered methods are usually applicable to short-term, inpatient settings. Long-term and outpatient 
monitoring requires untethered implantable devices that transmit data via telemetry. These devices have demonstrated a good safety profile, effectiveness, reliability and ease of use in animals. ${ }^{32}$ At present, several prospective case series examine the use of these devices in humans. An implantable intraparenchymal telemetric probe (Neurovent-P-tel) does not require calibration and is compatible with magnetic resonance imaging (MRI) scanners up to 3 Tesla. This device has been investigated in multiple centers for hydrocephalus, shunt dysfunction, endoscopic third ventriculostomy failure, calibration of intraventricular shunts, monitoring of endoscopic third ventriculostomies, craniostenosis, normal pressure hydrocephalus, and pseudotumor cerebri in patients ranging from 1-91 years of age for a duration of monitoring ranging 3-409 days. ${ }^{43-47}$ Another telemetric device is the OSAKA telesensor (OSAKA telesensor; Nagano Keiki Seisakusyo Co. Ltd., Tokyo, Japan) which is an ICP sensor embedded in a vericular shunt for patients with hydrocephalus showed accurate ICP measurement, diagnosed shunt malfunction correctly and was calibratable for zero drift by comparing the ICP reading from the telesensor with the puncture pressure in the onoff valve. ${ }^{48}$ The use of these devices has not been investigated in the critical care setting.

\section{NON-INVASIVE METHODS OF ICP MONITORING}

The advantage of non-invasive methods is the relative safety, low cost and easy access. However, at the present time, non-invasive methods seem to have a common theme when effective: they may be able to confirm presence or absence of intracranial hypertension at best but they are unable to produce a surrogate numerical value that compares to the invasive methods of measuring ICP. As ICU management becomes more individualized these methods may provide further insight into the individual cerebral autoregulatory status in lieu of a pure numerical interpretation ICP values.

Tympanic membrane displacement (TMD) measures the displacement on the tympanic membrane in response to the stapedial or middle ear reflex. ${ }^{49}$ Significant differences in the TM displacement have been found between patients with raised and normal ICP. ${ }^{50} \mathrm{TMD}$ is mostly studied in children, it shows some benefit in monitoring a single patient longitudinally as an outpatient, decreasing the need for invasive ICP measurement in shunted patients with hydrocephalus. However, at this point TCD remains a poor surrogate for ICP because the inter subject variability is high and the predictive value of the technique is low. ${ }^{50-52}$ Another limitation is the that TMD measurement requires an intact tympanic membrane and perilymphatic duct which may limit its use in trauma patients. ${ }^{32}$

As the use of ultrasound as a bedside technique in the critical care setting increases, measurements of optic nerve sheath diameter (ONSD) are more commonly used as a surrogate marker of elevated ICP. The optic nerve is surrounded by meningeal layers. The subarachnoid space surrounding the optic nerve is in continuation with that surrounding the brain. Thus, an increase in ICP may result in the expansion of the perineural optic nerve subarachnoid space which may be measured clinically as an increase in optic nerve sheath diameter (ONSD). ${ }^{53}$ ONSD can be measured using computed tomography (CT ), MRI or ultrasound. ${ }^{54,55}$ In a study of 59 patients, ONSD of $>5 \mathrm{~mm}$ on ocular ultrasound was shown to have $100 \%$ sensitivity and $83 \%$ specificity in detecting cranial CT findings of shift, edema, or effacement. ${ }^{56}$ In a study of 62 patients, the largest ONSD value was significantly higher in high ICP patients (patients with $\mathrm{ICP}>20 \mathrm{mmHg}$ for $>30 \mathrm{~min}$ in the first $48 \mathrm{~h}$ ) when compared to controls with no head injury. ${ }^{57}$ A recent metaanalysis concluded that ONSD sonography is a sensitive test for ruling out raised ICP in a low-prevalence population and a specific test for ruling in raised ICP in a higherprevalence population. When compared to CT-measured ONSD, ultrasound ONSD had a sensitivity of 95.6\% (95\% $\mathrm{Cl}, 87.7-98.5 \%)$ and specificity of $92.3 \%(95 \% \mathrm{Cl}, 77.9-$ $98.4 \%$ ) for diagnosing intracranial hypertension. ONSD > 5 $\mathrm{mm}$ predicts an ICP $>20 \mathrm{mmHg}$. However, ONSD is unable to produce a surrogate ICP value by itself. ${ }^{55}$ Measuring the optic canal via CT, excluding patients with an optic canal < 
$10 \mathrm{~mm}^{2}$ as patients with narrow canals had false negative readings, prior to using ONSD to predict ICP may improve the sensitivity of this method. ${ }^{58}$

The use of intraocular pressure (IOP) as an ICP indicator has also been investigated. The CSF communication between the intracranial subarachnoid space and optic nerve perineural subarachnoid space allows for ICP transmission into the eye which may be reflected as an increase in IOP. In a small pilot study of 27 patients, all patients with an abnormal ICP had an abnormal intraocular pressure; similarly, all patients with a normal ICP had a normal intraocular pressure. ${ }^{59}$ However, multiple subsequent studies have not demonstrated consistent findings. ${ }^{60-62}$

Transcranial Doppler (TCD) uses ultrasound waves to measure the velocity of blood flow in cerebral blood vessels. The ratio of the difference in systolic and diastolic flow velocity to mean flow velocity is referred to as the pulsatility index (PI). Other measures include estimated CPP and mathematical models based on similar principles of measuring the effect of the interaction between extravascular pressure in the form ICP and intravascular blood pressure on the flexible arterial wall. ${ }^{63}$ Potential advantages of using TCD in estimating ICP include portability, noninvasiveness, wide availability and the ability to perform repeated measures at the bed side with high temporal resolution. Disadvantages include reported false positive cases in patients that are hyperventilating, patients with diffuse intravascular disease, hyperdynamic circulatory states and severe cardiac regurgitation. In addition, up to $8 \%$ of patients do not have an adequate acoustic window for artery insonation and TCD may be limited to detecting ICP changes of vasogenic origin and be less sensitive with other pathological processes. ${ }^{63-66}$

Transcranial ultrasound can also be used to measure septum pallucidum undulations (SPU). In this test, the capability of the septum pellucidum to undulate relative to the ventricular wall during short (20-degree) rotatory movements of the head was related to ICP. If the ICP is elevated the septum pallucidum will be taught and undulate with amplitudes similar to that of the surrounding brain parenchyma and ventricles. In physiological conditions, the relaxed septum pallucidum undulates at higher amplitudes than the surrounding structures. This was reported to reflect ICP $>20 \mathrm{mmH}_{2} \mathrm{O}$ as confirmed by spinal tap. ${ }^{67} \mathrm{An}$ other study validated this technique showing sensitivity of $75 \%$ and specificity of $100 \%(n=32, p<0.001)$ in predicting $\mathrm{ICP}>20 \mathrm{mmH}_{2} \mathrm{O}^{68}$

Pulsed phase lock loop (PPLL) is another ultrasoundbased technique. A PPLL device generates an ultrasound signal that is transmitted through the temporal bone, travels through the brain tissue and is reflected by the contralateral side of the skull back to the transducer. The PPLL device then records slight movement (several microns) of the skull associated with ICP pulsations. ${ }^{69}$ This was validated in a single small study were ICP waveforms recorded by PPLL technique were correlated with invasively measured ICP waveforms using a fiberopticparenchymal device in 13 patients. This showed a high correlation between ICP waveforms recorded by PPLL and invasively. While this technology appears promising, it is limited to recording waveforms and is not able to record ICP as a numerical value. ${ }^{70}$

\section{BRAIN EDEMA MONITORING}

ICP monitoring has been the most readily available monitoring method for patients with brain injury, mainly because of the lack of a continuous reliable method of measuring brain edema. MRI and CT scans have been the method of choice for visualizing cerebral edema. ${ }^{71,72} \mathrm{Ad}$ vantages of imaging lies in its non-invasiveness. Extended CT perfusion (CTP) imaging has been used to estimate blood-brain barrier permeability by calculating the bidirectional washout rates of contrast between the vascular space to the extravascular extracellular space and viceversa. Extended CTP can also be used to calculate plasma flow, extravascular extracellular space volume per unit of tissue volume (VE) and plasmatic volume per unit of tissue volume (VP). ${ }^{73}$ Sulcal volume measurements have been used as a method of quantifying cerebral edema on CT. Decreased sulcal volume has been shown to be a marker associated with worse clinical outcomes after SAH. Further 
automation of sulcal volumes may be valuable method of estimating on going cerebral edema. ${ }^{74}$ Despite advancement of CT and MRI technology for imaging brain edema, the clinical utility for monitoring on-going cerebral edema is limited by high resource utilization of imaging and very intermittent measurements.

\section{INVASIVE REAL TIME MONITORING}

Recently, several methods have been developed to measure the brain water content and brain edema in real-time both invasively and non-invasively. These methods have the potential to measure cerebral edema and change the dynamics of monitoring for secondary brain injury in the neurocritical care setting.

Thermal diffusion probes have been used to estimate cerebral blood flow using the principle of thermal diffusion. By directly measuring the brain tissue's ability to transport heat and separating the conductive component of heat transfer through the brain tissue, the convective heat transfer due to perfusion can be calculated. The convective component of heat transfer is then used to calculate cerebral blood flow. ${ }^{75-77}$ Using the same probe, it is possible to calculate the brain water content (BWC) by measuring the thermal conductivity of the surrounding brain tissue. This novel method requires further studies to confirm its utility. ${ }^{78}$ The strength of this method lies in the continuous measure of cerebral edema; the limitation being it measures only local brain water content in brain tissue directly around the probe.

Ion selective electrodes (ISES) can measure the interstitial concentrations of sodium and potassium. ${ }^{79-81}$ Sodiumpotassium ATPase dysfunction with resultant increase in extracellular potassium and intracellular sodium have been implicated in cerebral edema secondary to brain. ${ }^{82}$ By utilizing an electrode covered by an ion-selective membrane, ISEs can convert the concentration of a specific ion into an electrical potential that can be measured as an output signal. ${ }^{79}$ This technique has been studied in rodents. Itshowed a significant controlled cortical injury-induced decrease in
$\mathrm{Na}+$ and increase in $\mathrm{K}+$ as well as faster recovery in these concentrations with Vasopressin-1a receptor ( $\mathrm{V} 1 \mathrm{aR})$ inhibition. ${ }^{81}$ These electrodes are largely used in animal research and have limitations including their size, their use of fragile glass capillary tubes that are time-consuming to prepare, and their inability to measure at more than one depth. Recent miniaturization and improvements of the design shows promise for potential use in clinical practice. ${ }^{80}$

Electrical resistance probes (ERP) use the concept of electrical impedance, the measure of opposition of brain tissue to an electrical current. Invasive ERP is used to detect cerebral edema at the cellular level in rodent studies. ${ }^{83}$ This method has not been used in clinical practice. However, the non-invasive method of cerebral electrical impedance has been studied clinically to monitor cerebral edema at the hemispheric level.

\section{NON-INVASIVE REAL TIME MONITORING}

Cerebral electrical impedance (CEI) uses the same principle of electrical impedance to measure the brain water content and cerebral edema. The patient's head is shaved and two electrodes are placed frontally and mid-occipitally. A constant current is applied to the patient's brain and impedence is recorded. ${ }^{84}$ Multiple small studies have shown that an increase in hemispheric electrical impedance corresponds to an increase cerebral edema with ischemic stroke and perihematomal edema with $\mathrm{ICH}^{84-87}$

Non-invasive Near Infrared Spectroscopy (NIRS) has been investigated to monitor cerebral blood flow and cerebral blood oxygenation intraoperatively and in the critical care setting. ${ }^{88-90}$ Because a near infrared light scattering signal (NIRSS) is directly proportional to brain water content, NIRSS may be used to detect small amounts of brain swelling. NIRSS has been shown in animal models to measure increases in brain swelling, but was insensitive to changes in cerebral blood flow, blood oxygenation, or blood flowrelated changes in ICP. An increase in NIRSS was detectable prior to increases in ICP when caused by edema. ${ }^{83,91}$ While this method is yet to be validated extensively in humans, it 
was used in a small cohort as surrogate for increased cerebral edema in mountain sickness and patients with symptoms of acute mountain sickness (AMS) showed higher NIRSS values. ${ }^{92}$ This study demonstrates the feasibility of using NIRSS to monitor changes in cerebral edema but more robust studies are needed to validate NIRSS as a surrogate for cerebral edema in humans.

\section{BLOOD TESTS}

A serum marker for cerebral edema or brain injury has been sought for decades. Similar to the "troponin of the brain" a serum marker would be non-invasive and could be monitored serially. Several markers have been proposed as markers of cerebral edema.

Endothelin-1 (ET-1) is a potent vasoconstrictor implicated in the pathogenesis of multiple brain injuries. It is implicated in increased BBB permeability leading to increased cerebral edema and infarct size in ischemic stroke. ${ }^{93}$ The blockade of ET-1 in multiple ischemic stroke models has been shown to decrease secondary brain injury. ${ }^{94,95} \mathrm{In}$ creased peri-hematomal ET-1 levels have been associated with increased BBB and worsening peri-hematomal edema in intracranial hemorrhage models. ${ }^{96}$ Increased expression of ET-1 has been shown in traumatic brain injury (TBI) models and is associated with increased vasospasm and ischemia. ${ }^{97}$ All this makes ET-1 a potential target for predicting the severity of secondary brain injury and developing therapeutic agents. ET-1 has been shown to predict the development of severe brain edema in ischemic stroke patient post Tpa. ${ }^{98} \mathrm{ET}-1$ has also been shown to be a predictor of vasospasm in TBI patients ET..$^{99-102}$ Current studies are limited by small sample sizes and more robust studies are needed to characterize the role of ET-1 levels in cerebral pathology. ET-1 may become a useful tool for predicting which patients may be at a higher risk to develop cerebral edema.

Matrix metalloproteinase-9 (MMP-9) is a proteolytic enzyme involved in remodeling the basal lamina and extracellular matrix. ${ }^{103}$ Increased MMP-9 expression has been detected in ischemic stroke and has been associated with higher NIHSS, larger infarct sizes and risk for hemorrhagic transformation. ${ }^{104-106}$ Cellular-fibronectin (c-Fn), a component of the basal lamina, has been shown to be more sensitive than MMP-9 in in the prediction of the edema development and malignant MCA syndrome. ${ }^{107}$ Further studies are needed to characterize the utility of MMP-9 and c-Fn in the evaluation of cerebral edema and secondary brain injury.

\section{CONCLUSION}

Our understanding of the value of monitoring cerebral hemodynamics has been challenged by multiple recent studies. It is important to remember that monitoring ICP or edema by itself would never effect therapeutic outcomes; therapeutic trials evaluate the effectiveness of specific therapies in reducing morbidity rather than the effectiveness of the diagnostic modality used. That said, the value of the various monitoring methods discussed lies in the potential to improve our understanding of cerebral hemodynamics and physiology. Non-invasive techniques will allow us to monitor a broader population of patients and thus add to the overall understanding of cerebral edema. As technology advances, our ability to monitor cerebral hemodynamics and cerebral edema will continue to improve. Failure of clinical trials using monitoring devices are not failure of the devices but rather failures of the treatments used to treat the underlying pathophysiology. Without effective treatments for cerebral edema which tackle the underlying pathophysiology, monitoring devices, no matter how accurately they measure and record, will not translate into clinical benefit. Attention needs to focus on novel methods of treating ICP elevation and brain edema.

\section{REFERENCES}

1. Chesnut RM, Bleck TP, Citerio G, Classen J, Cooper DJ, Coplin WM, et al. A consensus-based interpretation of the benchmark evidence from South American trials: treatment of intracranial 
pressure trial. / Neurotrauma 2015;32:1722-4.

2. Chesnut RM, Temkin N, Carney N, Dikmen S, Rondina C, Videtta $W$, et al. A trial of intracranial-pressure monitoring in traumatic brain injury. N Engl / Med 2012;367:2471-81.

3. Hutchinson PJ, Kolias AG, Timofeev IS, Corteen EA, Czosnyka M, Timothy J, et al. Trial of decompressive craniectomy for traumatic intracranial hypertension. N Engl / Med 2016;375:1119-30.

4. Cooper DJ, Rosenfeld JV, Murray L, Arabi YM, Davies AR, D'Urso $P$, et al. Decompressive craniectomy in diffuse traumatic brain injury. N Engl / Med2011;364:1493-502.

5. Andrews PJ, Sinclair HL, Rodriguez A, Harris BA, Battison CG, Rhodes JK, et al. hypothermia for intracranial hypertension after traumatic brain injury. N Engl / Med 2015;373:240312.

6. Choi HA, Bajgur SS, Chang TR. The Role of Intracranial Multimodality Monitoring Strategies. In: Konig M, ed. Cerebral Herniation Syndromes and INtracrnail Hypertension (Updates in Neurocritical Care). 1st ed. New Brunswick, New Jersey: Rutgers University Press 2015; 191.

7. Choi HA, Bajgur SS, Chang TR. The Role of Intracranial Pressure in Multimodality Monitoring Strategies. In: Koenig M, ed. Cerebral Herniation Syndromes and Intracranial Hypertension (Updates in Neurocritical Care). 1st ed. New Brunswick, New Jersey: Rutgers University Press 2015;189-218.

8. Perez-Barcena J, Llompart-Pou JA, O’Phelan KH. Intracranial pressure monitoring and management of intracranial hypertension. Crit Care Clin 2014;30:735-50.

9. Smith M. Monitoring intracranial pressure in traumatic brain injury. Anesth Analg 2008;106:240-8.

10. Sahuquillo J, Poca MA, Arribas M, Garnacho A, Rubio E. Interhemispheric supratentorial intracranial pressure gradients in head-injured patients: are they clinically important? / Neurosurg 1999;90:16-26.

11. Mindermann T, Gratzl O. Interhemispheric pressure gradients in severe head trauma in humans. Acta Neurochir Suppl 1998; $71: 56-8$

12. Moyse E, Ros M, Marhar F, Swider P, Schmidt EA. Characterisation of supra- and infratentorial ICP profiles. Acta Neurochir Supp/ 2016;122:37-40.

13. Brain Trauma Foundation; American Association of Neurological Surgeons; Congress of Neurological Surgeons; Joint Section on Neurotrauma and Critical Care, AANS/CNS, Bratton SL, Chestnut RM, et al. Guidelines for the management of severe traumatic brain injury. VIII. Intracranial pressure thresholds./ Neurotrauma2007;24(Suppl 1):S55-8

14. Carney N, Totten AM, O'Reilly C, et al. Guidelines for the Management of Severe Traumatic Brain Injury, Fourth Edition. Neurosurgery. 2016.[Epub ahead of print]

15. Marshall LF, Barba D, Toole BM, Bowers SA. The oval pupil: clinical significance and relationship to intracranial hypertension. / Neurosurg 1983;58:566-8.

16. Andrews BT, Chiles BW 3rd, Olsen WL, Pitts LH. The effect of intracerebral hematoma location on the risk of brainstem compression and on clinical outcome. / Neurosurg 1988;69:518-22.

17. Doyle DJ, Mark PW. Analysis of intracranial pressure. / Clin Monit 1992:8:81-90.

18. Fan JY, Kirkness C, Vicini P, Burr R, Mitchell P. An approach to determining intracranial pressure variability capable of predicting decreased intracranial adaptive capacity in patients with traumatic brain injury. Biol Res Nurs 2010;11:317-24.

19. Eide PK, Bakken A. The baseline pressure of intracranial pressure (ICP) sensors can be altered by electrostatic discharges. Biomed Eng Online 2011;10:75.

20. Gega A, Utsumi S, lida Y, lida N, Tsuncda S. Analysis of the wave pattern of CSF pulse wave. In: Intracranial pressure IV. Berlin, Heidelberg: Springer Berlin Heidelberg 1980:188-90.

21. Cardoso ER, Rowan JO, Galbraith S. Analysis of the cerebrospinal fluid pulse wave in intracranial pressure. / Neurosurg 1983;59:817-21.

22. Lundberg N, Troupp $H$, Lorin $H$. Continuous recording of the ventricular-fluid pressure in patients with severe acute traumatic brain injury. A preliminary report. / Neurosurg $1965 ; 22: 581-90$

23. Lundberg N. Continuous recording and control of ventricular fluid pressure in neurosurgical practice. Acta Psychiatr Scand Supp/1960;36:1-193.

24. Spiegelberg A, Preuß M, Kurtcuoglu V. B-waves revisited. Interdiscip Neurosurg 2016:6:13-7.

25. Paulson OB, Strandgaard S, Edvinsson L. Cerebral autoregulation. Cerebrovasc Brain Metab Rev 1990;2:161-92.

26. Steiner LA, Czosnyka M, Piechnik SK, Smielewski P, Chatfield D, Menon DK, et al. Continuous monitoring of cerebrovascular pressure reactivity allows determination of optimal cerebral perfusion pressure in patients with traumatic brain injury. Crit Care Med2002;30:733-8.

27. Czosnyka M, Smielewski P, Kirkpatrick P, Piechnik S, Laing R, Pickard JD. Continuous monitoring of cerebrovascular pressure-reactivity in head injury. Acta Neurochir Suppl 
1998;71:74-7.

28. Sánchez-Porras R, Santos E, Czosnyka M, Zheng Z, Unterberg AW, Sakowitz OW. "Long" pressure reactivity index (L-PRx) as a measure of autoregulation correlates with outcome in traumatic brain injury patients. Acta Neurochir (Wien) 2012;154:1575-81.

29. Lang EW, Kasprowicz M, Smielewski P, Santos E, Pickard J, Czosnyka M. Short pressure reactivity index versus long pressure reactivity index in the management of traumatic brain injury. / Neurosurg 2015;122:588-94.

30. Czosnyka M, Guazzo E, Whitehouse M, Smielewski P, Czosnyka Z, Kirkpatrick P, et al. Significance of intracranial pressure waveform analysis after head injury. Acta Neurochir (Wien) 1996;138:531-41; discussion 541-2.

31. Eide PK, Sorteberg A, Meling TR, Sorteberg W. The effect of baseline pressure errors on an intracranial pressure-derived index: results of a prospective observational study. Biomed Eng Online 2014;13:99.

32. Kawoos U, McCarron RM, Auker CR, Chavko M. Advances in intracranial pressure monitoring and its significance in managing traumatic brain injury. Int / Mol Sci 2015;16:2897997.

33. Brain Trauma Foundation, American Association of Neurological Surgeons, Congress of Neurological Surgeons, et al. Guidelines for the management of severe traumatic brain injury. VIII. Intracranial pressure thresholds. / Neurotrauma 2007;24(Suppl 1):S55-8.

34. Zhong J, Dujovny M, Park HK, Perez E, Perlin AR, Diaz FG. Advances in ICP monitoring techniques. Neurol Res 2003;25:339-50.

35. Raboel PH, Bartek / Jr, Andresen M, Bellander BM, Romner B. Intracranial pressure monitoring: invasive versus non-invasive methods-a review. Crit Care Res Pract2012;2012:950393.

36. Mayhall CG, Archer NH, Lamb VA, Spadora AC, Baggett JW, Ward JD, et al. Ventriculostomy-Related Infections. N Eng/ I Med 1984;310:553-9.

37. Lozier AP, Sciacca RR, Romagnoli MF, Connolly ES Jr. Ventriculostomy-related infections: a critical review of the literature. Neurosurgery 2002;51:170-81; discussion 181-2.

38. Zabramski JM, Whiting D, Darouiche RO, Horner TG, Olson J, Robertson C, et al. Efficacy of antimicrobial-impregnated external ventricular drain catheters: a prospective, randomized, controlled trial. / Neurosurg 2003;98:725-30.

39. Binz DD, Toussaint LG 3rd, Friedman JA. Hemorrhagic Complications of Ventriculostomy Placement: A Meta-Analysis.
Neurocrit Care 2009;10:253-6.

40. Martínez-Mañas RM, Santamarta D, de Campos JM, Ferrer E. Camino intracranial pressure monitor: prospective study of accuracy and complications. / Neurol Neurosurg Psychiatry 2000;69:82-6.

41. Lescot T, Reina V, Le Manach Y, Boroli F, Chauvet D, Boch $A L$, et al. In vivo accuracy of two intraparenchymal intracranial pressure monitors. Intensive Care Med 2011;37:875-9.

42. Koskinen LO, Olivecrona M. Clinical experience with the intraparenchymal intracranial pressure monitoring Codman MicroSensor system. Neurosurgery 2005;56:693-8; discussion 693-8.

43. Welschehold S, Schmalhausen E, Dodier P, Vulcu S, Oertel J, Wagner W, et al. First clinical results with a new telemetric intracranial pressure-monitoring system. Neurosurgery 2012;70(1 Suppl Operative):44-9; discussion 49.

44. Lilja A, Andresen M, Hadi A, Christoffersen D, Juhler M. Clinical experience with telemetric intracranial pressure monitoring in a Danish neurosurgical center. Clin Neurol Neurosurg 2014; 120:36-40.

45. Antes S, Tschan CA, Kunze G, Ewert L, Zimmer A, Halfmann $A$, et al. Clinical and radiological findings in long-term intracranial pressure monitoring. Acta Neurochir (Wien) 2014;156:1009-19; discussion 1019.

46. Freimann FB, Schulz M, Haberl H, Thomale UW. Feasibility of telemetric ICP-guided valve adjustments for complex shunt therapy. Childs Nerv Syst 2014;30:689-97.

47. Antes S, Tschan CA, Oertel JM. An operative technique combining endoscopic third ventriculostomy and long-term ICP monitoring. Childs Nerv Syst 2014;30:331-5.

48. Miyake H, Ohta T, Kajimoto Y, Matsukawa M. A new ventriculoperitoneal shunt with a telemetric intracranial pressure sensor: clinical experience in 94 patients with hydrocephalus. Neurosurgery 1997;40:931-5.

49. Marchbanks RJ, Reid A, Martin AM, Brightwell AP, Bateman D. The effect of raised intracranial pressure on intracochlear fluid pressure: three case studies. Br J Audio/ 1987;21:127-30.

50. Reid A, Marchbanks RJ, Burge DM, Martin AM, Bateman $D E$, Pickard JD, et al. The relationship between intracranial pressure and tympanic membrane displacement. Br J Audiol 1990;24:123-9.

51. Shimbles S, Dodd C, Banister K, Mendelow AD, Chambers IR. Clinical comparison of tympanic membrane displacement with invasive intracranial pressure measurements. Physiol Meas 2005;26:1085-92. 
52. Shimbles S, Dodd C, Banister K, Mendelow AD, Chambers IR. Clinical comparison of tympanic membrane displacement with invasive ICP measurements. Acta Neurochir Suppl 2005;95:197-9.

53. Hansen HC, Helmke K. Validation of the optic nerve sheath response to changing cerebrospinal fluid pressure: ultrasound findings during intrathecal infusion tests. / Neurosurg 1997:87:34-40.

54. Shofty B, Ben-Sira L, Constantini S, Freedman S, Kesler A. Optic nerve sheath diameter on MR imaging: establishment of norms and comparison of pediatric patients with idiopathic intracranial hypertension with healthy controls. Am J Neuroradiol 2012:33:366-9.

55. Ohle R, Mclsaac SM, Woo MY, Perry IJ. Sonography of the optic nerve sheath diameter for detection of raised intracranial pressure compared to computed tomography: a systematic review and meta-analysis. / Ultrasound Med 2015;34:1285-94

56. Tayal VS, Neulander M, Norton HJ, Foster T, Saunders T, Blaivas M. Emergency department sonographic measurement of optic nerve sheath diameter to detect findings of increased intracranial pressure in adult head injury patients. Ann Emerg Med 2007:49:508-14.

57. Geeraerts T, Launey Y, Martin L, Pottecher J, Vigué B, Duranteau J, et al. Ultrasonography of the optic nerve sheath may be useful for detecting raised intracranial pressure after severe brain injury. Intensive Care Med 2007;33:1704-11

58. Bekerman I, Kimiagar I, Sigal T, Vaiman M. Monitoring of intracranial pressure by CT-defined optic nerve sheath diameter. / Neuroimaging 2016;26:309-14.

59. Lashutka MK, Chandra A, Murray HN, Phillips GS, Hiestand $B C$. The relationship of intraocular pressure to intracranial pressure. Ann Emerg Med 2004;43:585-91.

60. Nabeta HW, Bahr NC, Rhein J, Fossland N, Kiragga AN, Meya $D B$, et al. Accuracy of noninvasive intraocular pressure or optic nerve sheath diameter measurements for predicting elevated intracranial pressure in cryptococcal meningitis. Open forum Infect Dis 2014;1:ofu093.

61. Czarnik T, Gawda R, Latka D, Kolodziej W, Sznajd-Weron K, Weron R. Noninvasive measurement of intracranial pressure: is it possible? / Trauma 2007;62:207-11.

62. Kirk T, Jones K, Miller S, Corbett J. Measurement of intraocular and intracranial pressure: is there a relationship? Ann Neurol 2011;70:323-6.

63. Cardim D, Robba C, Bohdanowicz M, Donnelly J, Cabella B,
Liu $X$, et al. Non-invasive monitoring of intracranial pressure using transcranial Doppler ultrasonography: Is It possible? Neurocritical Care 2016:1-19.

64. Wakerley B, Yohana K, Luen Teoh H, Tan CW, Chan BP, Sharma VK. Non-invasive intracranial pressure monitoring with transcranial Doppler in a patient with progressive cerebral venous sinus thrombosis. / Neuroimaging 2014;24:302-4

65. Maeda H, Matsumoto M, Handa N, Hougaku H, Ogawa $\mathrm{S}$, Itoh $\mathrm{T}$, et al. Reactivity of cerebral blood flow to carbon dioxide in various types of ischemic cerebrovascular disease: evaluation by the transcranial Doppler method. Stroke 1993:24:670-5.

66. Sloan MA, Alexandrov AV, Tegeler CH, Spencer MP, Caplan $L R$, Feldmann E, et al. Assessment: transcranial Doppler ultrasonography: report of the Therapeutics and Technology Assessment Subcommittee of the American Academy of Neurology. Neurology 2004;62:1468-81.

67. Becker G, Bogdahn U, Strassburg HM, Lindner A, Hassel W, Meixensberger I, et al. Identification of ventricular enlargement and estimation of intracranial pressure by transcranial color-coded real-time sonography. / Neuroimaging 1994; 4:17-22.

68. Bolesch S, von Wegner F, Senft C, Lorenz MW. Transcranial ultrasound to detect elevated intracranial pressure: Comparison of septum pellucidum undulations and optic nerve sheath diameter. Ultrasound Med Biol 2015;41:1233-40.

69. Ueno T, Macias BR, Hargens AR, Yost WT. Pulsed phase lock loop technique to measure intracranial pressure noninvasively. IEEE Symp UItrason 2003. 2003;2:1215-8.

70. Ueno T, Macias BR, Yost WT, Hargens AR. Noninvasive assessment of intracranial pressure waveforms by using pulsed phase lock loop technology. Technical note. / Neurosurg 2005;103:361-7.

71. Currie S, Saleem N, Straiton JA, Macmullen-Price I, Warren D), Craven IJ. Imaging assessment of traumatic brain injury. Postgrad Med / 2016;92:41-50

72. Fink KR, Benjert JL. Imaging of nontraumatic neuroradiology emergencies. Radiol Clin North Am 2015;53:871-90, x.

73. Ivanidze I, Kallas ON, Gupta A, Weidman E, Baradaran H, Mir D, et al. Application of blood-brain barrier permeability imaging in global cerebral edema. A/NR Am / Neuroradiol 2016;37:1599-603.

74. Choi HA, Bajgur SS, Jones WH, Savarraj JP, Ko SB, Edwards N), et al. Quantification of Cerebral Edema After Subarachnoid Hemorrhage. Neurocrit Care 2016;25:64-70. 
75. Vajkoczy P, Roth H, Horn P, Lucke T, Thomé C, Hubner U, et al. Continuous monitoring of regional cerebral blood flow: experimental and clinical validation of a novel thermal diffusion microprobe. / Neurosurg 2000;93:265-74.

76. Jaeger M, Soehle M, Schuhmann MU, Winkler D, Meixensberger J. Correlation of continuously monitored regional cerebral blood flow and brain tissue oxygen. Acta Neurochir (Wien) 2005;147:51-6; discussion 56.

77. Rosenthal G, Sanchez-Mejia RO, Phan N, Hemphill JC 3rd, Martin C, Manley GT. Incorporating a parenchymal thermal diffusion cerebral blood flow probe in bedside assessment of cerebral autoregulation and vasoreactivity in patients with severe traumatic brain injury. / Neurosurg 2011;114:62-70.

78. Ko SB, Choi HA, Parikh G, Schmidt JM, Lee K, Badjatia N, et al. Real time estimation of brain water content in comatose patients. Ann Neuro/2012;72:344-50.

79. van de Velde L, d'Angremont E, Olthuis W. Solid contact potassium selective electrodes for biomedical applications - a review. Talanta 2016;160:56-65.

80. Odijk M, van der Wouden EJ, Olthuis W, Ferrari MD, Tolner EA, van den Maagdenberg AM, al. Microfabricated solid-state ion-selective electrode probe for measuring potassium in the living rodent brain: Compatibility with DC-EEG recordings to study spreading depression. Sensors Actuators B Chem 2015;207:945-53

81. Filippidis AS, Liang X, Wang W, Parveen S, Baumgarten CM, Marmarou CR. Real-time monitoring of changes in brain extracellular sodium and potassium concentrations and intracranial pressure after selective vasopressin-1a receptor inhibition following focal traumatic brain injury in rats. / Neurotrauma 2014;31:1258-67.

82. Vexler ZS, Roberts TP, Kucharczyk J, Arieff Al. Severe brain edema associated with cumulative effects of hyponatremic encephalopathy and ischemic hypoxia. Acta Neurochir Suppl (Wien) 1994;60:246-9.

83. Demirci M, Ayata C, Dalkara T, Erdemli G, Onur R. Monitoring cellular edema at single-neuron level by electrical resistance measurements. / Neurosci Methods 1997;72:175-81.

84. Liu LX, Dong WW, Wang J, Wu Q, He W, Jia YJ. The role of noninvasive monitoring of cerebral electrical impedance in stroke. Acta Neurochir Supp/ 2005;95:137-40.

85. He LY, Wang J, Luo Y, Dong WW, Liu LX. Application of non-invasive cerebral electrical impedance measurement on brain edema in patients with cerebral infarction. Neurol Res 2010;32:770-4.
86. Liu L, Dong W, Ji X, Chen L, Chen L, He W, et al. A new method of noninvasive brain-edema monitoring in stroke: cerebral electrical impedance measurement. Neurol Res 2006;28:31-7.

87. Lou JH, Wang J, Liu LX, He LY, Yang H, Dong WW. Measurement of brain edema by noninvasive cerebral electrical impedance in patients with massive hemispheric cerebral infarction. Eur Neurol 2012;68:350-7.

88. Ghosh A, Elwell C, Smith M. Review article: cerebral nearinfrared spectroscopy in adults: a work in progress. Anesth Analg 2012;115:1373-83.

89. Taillefer MC, Denault AY. Cerebral near-infrared spectroscopy in adult heart surgery: systematic review of its clinical efficacy. Can J Anaesth 2005;52:79-87.

90. Madsen PL, Secher NH. Near-infrared oximetry of the brain. Prog Neurobio/ 1999;58:541-60.

91. Thiagarajah JR, Papadopoulos MC, Verkman AS. Noninvasive early detection of brain edema in mice by near-infrared light scattering. / Neurosci Res 2005;80:293-9.

92. DiPasquale DM, Muza SR, Gunn AM, Li Z, Zhang Q, Harris NS, et al. Evidence for cerebral edema, cerebral perfusion, and intracranial pressure elevations in acute mountain sickness. Brain Behav 2016;6:e00437.

93. Lo AC, Chen AY, Hung VK, Yaw LP, Fung MK, Ho MC, et al. Endothelin-1 overexpression leads to further water accumulation and brain edema after middle cerebral artery occlusion via aquaporin 4 expression in astrocytic end-feet. / Cereb Blood Flow Metab 2005;25:998-1011.

94. Dawson DA, Sugano H, McCarron RM, Hallenbeck JM, Spatz M. Endothelin receptor antagonist preserves microvascular perfusion and reduces ischemic brain damage following permanent focal ischemia. Neurochem Res 1999;24:1499-505.

95. Barone FC, Ohlstein EH, Hunter A), Campbell CA, Hadingham $\mathrm{SH}$, Parsons AA, et al. Selective antagonism of endothelinA-receptors improves outcome in both head trauma and focal stroke in rat. / Cardiovasc Pharmacol 2000;36(5 Suppl 1):S357-61.

96. Wang LK, Hong Z, Wu GF, Li C. Perihematomal endothelin-1 level is associated with an increase in blood-brain barrier permeability in a rabbit model of intracerebral hematoma. Chin Med J (Engl) 2013;126:3433-8.

97. Sirén AL, Knerlich F, Schilling L, Kamrowski-Kruck H, Hahn A, Ehrenreich $\mathrm{H}$. Differential glial and vascular expression of endothelins and their receptors in rat brain after neurotrauma. Neurochem Res 2000;25:957-69.

98. Moldes O, Sobrino T, Millán M, Castellanos M, Pérez de la 
Ossa N, Leira R, et al. High serum levels of endothelin-1 predict severe cerebral edema in patients with acute ischemic stroke treated with t-PA. Stroke 2008;39:2006-10.

99. Sato M, Noble LJ. Involvement of the endothelin receptor subtype $A$ in neuronal pathogenesis after traumatic brain injury. Brain Res 1998;809:39-49.

100. Juvela S. Plasma endothelin concentrations after aneurysmal subarachnoid hemorrhage. / Neurosurg 2000;92:390-400.

101. Seifert V, Löffler BM, Zimmermann M, Roux S, Stolke D. Endothelin concentrations in patients with aneurysmal subarachnoid hemorrhage. Correlation with cerebral vaso

spasm, delayed ischemic neurological deficits, and volume of hematoma. / Neurosurg 1995;82:55-62.

102. Suzuki K, Meguro K, Sakurai T, Saitoh Y, Takeuchi S, Nose T. Endothelin-1 concentration increases in the cerebrospinal fluid in cerebral vasospasm caused by subarachnoid hemorrhage. Surg Neuro/ 2000;53:131-5

103. Romanic AM, Madri JA. Extracellular matrix-degrading pro- teinases in the nervous system. Brain Pathol 1994:4:145-56.

104. Clark AW, Krekoski CA, Bou SS, Chapman KR, Edwards DR. Increased gelatinase A (MMP-2) and gelatinase B (MMP-9) activities in human brain after focal ischemia. Neurosci Lett 1997;238:53-6.

105. Montaner J, Alvarez-Sabín J, Molina C, Anglés A, Abilleira S, Arenillas ], et al. Matrix metalloproteinase expression after human cardioembolic stroke: temporal profile and relation to neurological impairment. Stroke 2001;32:1759-66.

106. Castellanos M, Leira R, Serena J, Pumar JM, Lizasoain I, Castillo J, et al. Plasma metalloproteinase-9 concentration predicts hemorrhagic transformation in acute ischemic stroke. Stroke 2003:34:40-6.

107. Serena I, Blanco M, Castellanos M, Silva Y, Vivancos I, Moro $M A$, et al. The prediction of malignant cerebral infarction by molecular brain barrier disruption markers. Stroke 2005;36:1921-6. 